\title{
Cultural Artditivity
}

Quan-Hoang Vuong, Manh-Toan Ho, Manh-Tung Ho, Minh-Hoang Nguyen, HongKong T. Nguyen

AISDL

Hanoi, 10-01-2021

The old saying goes like this: "Every story has already been told." The quote points to the peculiar nature of arts: Storytelling is retelling a story. There are various versions of a story across cultures. For instance, even though Grimm's Fairy Tales is famous, they are adapted from the traditional tales by Grimm Brothers. Recently, adaptations of traditional stories or foreign scripts have become more common, especially in films or television. In certain countries, the course of history has allowed their arts or architecture to be entirely based on outside influences. During the French colonialization, Vietnamese art flourished with Asian concepts and Western techniques [1]. Similarly, old houses in Vietnam also blends elements of France and China [2].

As a cultural product, arts are generally comprehensible across cultures. However, even though every story has already been told, not every person resonates with a story similarly. In a way, the culture of a cultural product cannot be added to a person's core cultural value. As a consumer, a person needs to accept cultural elements in a story, even though those elements might contradict their existing beliefs [3]. The process of cultural additivity in experiencing arts can be explained by the mindsponge mechanism $[3,4]$.

In the original Infernal Affairs (2002), the story ends with (by the way, spoiler alerts) the antagonist stayed alive. Meanwhile, in the 2006 American remake, The Departed, the antagonist died. Here, you have to accept the cultural factor in the ending of each movie. Otherwise, one movie will always be inferior to the other. The original version underlines the concept of eternal suffering. The undercover lives of both main characters in the movie are comparable to a living hell, with endless deceptions and cautions. Thus, when the main protagonist died, he achieved liberation. On the contrary, the antagonist had to maintain his fake persona, continuing to a dishonest life. The American remake is more straightforward, and indeed, more American.

Which version works better is entirely personal. However, understanding cultural additivity can benefit the creative process. Vuong and Napier (2015) 
illustrated the mindsponge mechanism with a core of values, a comfort zone that protects the core, and a filter to evaluate new values [4]. So, when a fictional character acts in a certain way, you have to take into account various elements: his background, his motives, and his core values. For instance, Bruce Wayne wanted to become Batman because his parents passed away, he wanted to clean the street of Gotham, and most importantly, he is rich.

The establishment of a good story is providing sufficient information for the audience to relate with a character. Certainly, universal archetypes will work most of the time. The difference comes when you a piece of art stray away from the universal elements. In Boyz $n$ the Hood (1991), the director had to use various expositions to provide the audience with sufficient context. The opening scene with shocking statistics, or the scene about gentrification. This information is crucial for the audiences to understand the problems that Black American males face. The movie works because they let you into the life of Tre Styles, Doughboy, and Ricky Baker with preparation. Furthermore, thanks to the magic of the suspension of disbelief, the audience is entirely with the boys in their hood.

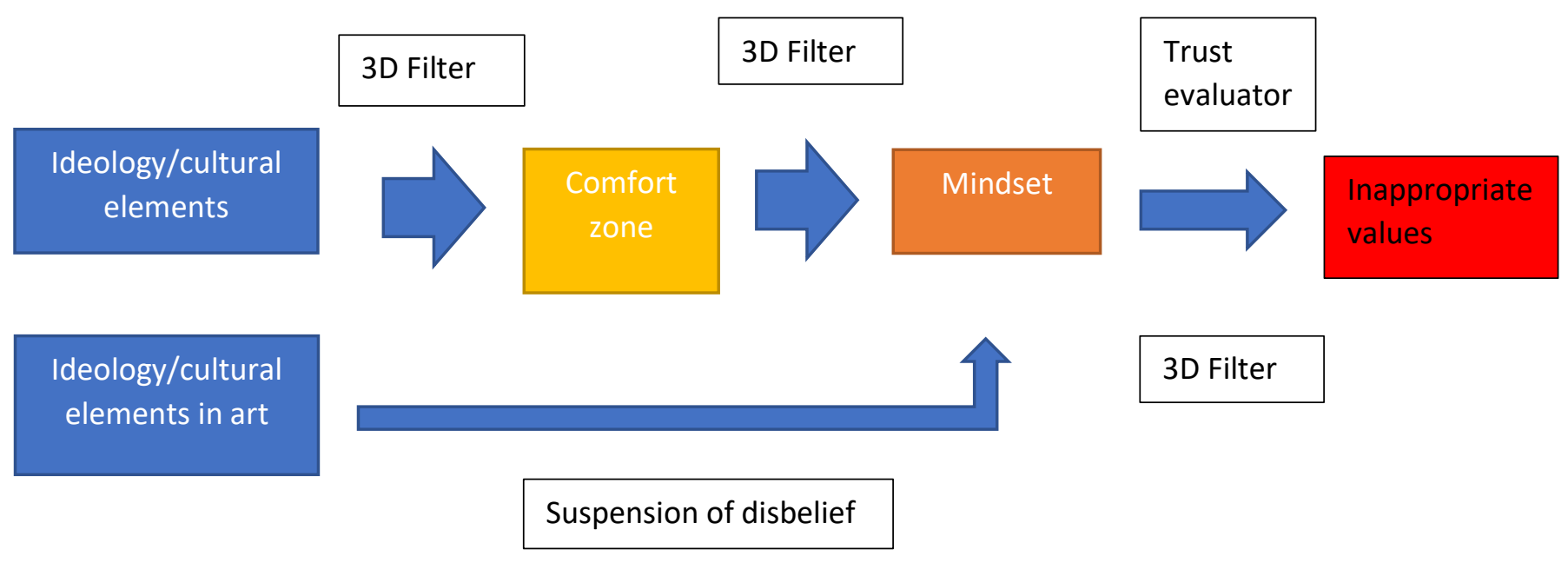

Figure 1. The cultural additivity of experiencing arts.

Here, several characteristics are notable. The cultural additivity process happens almost immediately when the consumption of a cultural product begins (See Figure 1). Here, due to the rapid nature of the form, the audience barely has anytime to filter the information. So, the suspension of disbelief helps the new 
values bypass the filter and the comfort zone. Moreover, arts also put the audience in a perpetual cycle of interpretation and re-interpretation. Most of the time, there is no binary conclusion, and each viewing will bring a different meaning to the text. In a way, if the text can make the audience think about it even after its conclusion, the process of cultural additivity continues. Only now, the 3D filter and the trust evaluator start working to evaluate the values from experience. There are two possibilities. First, the trust evaluator and the 3D filter work normally. Second, the trust evaluator and the 3D filter are now biased due to experiencing arts. Either way, the value of cultural additivity will be adjusted, sliding between 0 and 1 . If the filters work normally, the value of cultural additivity will not change dramatically. Meanwhile, the value of cultural additivity will increase significantly when the filters are biased.

The question is whether new cultural ideas are incorporated into their core values. Recent studies have suggested the vital role of art in generating empathy [5-8]. Hence, be it contrary or not, a new cultural value is acknowledged through the consumption of art. More specifically, the liveliness of the art-consuming experience allows the audience to adjust their cultural additivity spectrum more freely.

Here, I want to specifically discuss the role of video games. Video games are immersive. An average game player needs to spend at least 20 hours to complete a game. Recently, The Last of Us and its sequel have been braved enough to depict compelling moral issues. The sequel, The Last of Us Part 2 especially forces the player to play the antagonist. Nonetheless, this move does not sit well with fans, and many people have resent the producer for it. It is also hard to analyze the experience when the players spend a majority of game time to blow someone up.

However, virtual worlds in games have become more gigantic, rich, and immersive. For instance, the Assassin's Creed series replicated specific locations in a specific time: the Third Crusade, the Italian Renaissance era, the American Revolution, or ancient Egypt or Greece. It was fun to befriend Leonardo de Vinci or have a conversation with Socrates. The richness of these worlds, even though some have a look, can start the cultural additivity process.

There are still some problems. The language of game is unique and monotonous. They can be interesting, but they can also be culture-free. Thus, the introduction of new values is limited. The story in video games is also straightforward and archetypical. You are a hero. You have to save the world. The lack of compelling contexts hindered the accessibility to the contradiction of values. Thus, the player cannot be forced to start their cultural additivity process. Finally, while the passive forms of art lack time, the interactive forms have too much time. 


\section{References}

[1] Vuong, Q. H., Ho, M. T., Nguyen, H. K. T., Vuong, T. T., Tran, K., \& Ho, M. T. (2018). "Paintings can be forged, but not feeling": Vietnamese art-market, fraud, and value. Arts, 74 ), 62.

[2] Vuong, Q. H., Bui, Q. K., La, V. P., Vuong, T. T., Ho, T. M., et al. (2019). Cultural evolution in Vietnam's early 20th century: a Bayesian networks analysis of Hanoi Franco-Chinese house designs. Social Sciences \& Humanities Open, 1(1), 100001.

[3] Vuong, Q. H., La, V. P., Vuong, T. T., Nguyen, V. H., Ho, M. T., et al. (2018). Cultural additivity: Behavioural insights from the interaction of Confucianism, Buddhism, and Taoism in folktales. Palgrave Communications, 4, 143.

[4] Vuong, Q. H., \& Napier, N. K. (2015). Acculturation and global mindsponge: an emerging market perspective. International Journal of Intercultural Relations, 49, 354-367.

[5] Patel, S., Wallis-Redworth, M., Jackson, S., \& Rose, L. (2017). Art and science: promoting understanding and empathy through film. British Journal of Midwifery, 25(11), 734-740.

[6] Nåls, J. (2019). Making the strange familiar: the functions of empathy in intercultural film narrative (Dissertation, University of Helsinki, Finland). Available from https://www.theseus.fi/bitstream/handle/10024/303044/nals jan.pdf?sequ ence $=1$

[7] Bentwich, M. E., \& Gilbey, P. (2017). More than visual literacy: art and the enhancement of tolerance for ambiguity and empathy. BMC Medical Education, 1Л(1), 200.

[8] Stamatopoulou, D. (2018). Empathy and the aesthetic: Why does art still move us?. Cognitive Processing, 19(2), 169-186.

[9] Plante, C. (2020). The Last of Us 2 epitomizes one of gaming's longest debates. Polygon. Available from https://www.polygon.com/2020/6/26/21304642/the-last-of-us-2-violence 